\title{
The Effect of Surface Treatment and Adhesive System on the Durability of Composite Repairs
}

\section{Lukas Comba, Pavel Bradna*, Erika Lenčová, Jana Dušková and Děvana Houšová}

School of Dental Medicine, First Faculty of Medicine of the Charles University and General University Hospital in Prague, Karlovo namesti 32, Prague, 121 11, Czech Republic

\begin{abstract}
Controversy exists concerning the optimal procedure for composite restoration repairs. The aim of the study was to investigate the effect of surface treatment, adhesive system and long-term storage in water and a surfactant solution on the bond strength between aged and repair composite materials.

Surfaces of a light-cured micro-hybrid composite (Filtek Z250) aged in distilled water for five months at $37^{\circ} \mathrm{C}$ were treated by grinding with SiC paper $\mathrm{P} 320$ or by air abrasion (Rondoflex, $\mathrm{Al}_{2} \mathrm{O}_{3}, 50 \mu \mathrm{m}$ ). The build-ups were made with the same composite material using Optibond FL (OPF), Gluma Comfort Bond (GLU) and Clearfil SE Bond (CLF) adhesive systems. The build-ups were sectioned into sticks, stored at $37^{\circ} \mathrm{C}$ for four months in distilled water or in a solution of a surfactant sodium lauryl sulfate (SLS, $1.5 \mathrm{wt}$ \% ) to accelerate water penetration in the adhesive joint. Control specimens were stored in distilled water for $24 \mathrm{~h}$ at $37^{\circ} \mathrm{C}$. The results were analyzed with a three-way ANOVA followed by Fisher's LSD post-hoc tests at $\alpha=0.05$ and with Weibull statistics. The surface morphology of treated and fractured surfaces was analyzed using light and scanning electron microscopy. The bond strengths of the majority of groups treated by air abrasion were significantly higher and more stable after long-term storage in water and SLS solution than those treated by grinding. These results indicated that air abrasion combined with clinically well-proven adhesives may provide increased strength and long-term stability of composite repairs.
\end{abstract}

Keywords: Composite repair; Durability; Bond strength; Microtensile; Air abrasion

\section{Introduction}

Composite restorations in the oral cavity are exposed to an aggressive environment and mechanical challenge that gradually impairs their physical and mechanical properties. This may result in an enhanced wear rate, loss of esthetic properties and an increased risk of a restoration fracture or its marginal failure with a negative impact on the restoration's durability $[1,2]$. Worn or failed restorations are usually completely replaced, which increases the irreversible loss of dental hard tissues. Repair of composite restorations by their partial replacement is therefore a minimally invasive [3,4] and less time-consuming [5] alternative to their complete replacement and increases their longevity [6]. The major and not yet fully resolved issue of composite repairs is how to achieve a strong and durable bond between the existing and repair composite materials. It is generally supposed that the bond between them largely depends on micromechanical retention. Surface treatment therefore plays a key role in the repair of composite restorations. The surface of the restoration is most often mechanically treated using a diamond bur and air abrasion [7-22]. Such treatments remove the aged surface layer of the existing composite restoration and create irregularities, which increase the surface wettability, roughness and total surface area [23]. After the preparation, the surface is cleaned with phosphoric acid for debris and smear layer removal [18-20,22,2426], or by a hydrofluoric acid to dissolve silica filler particles and to enlarge surface area [7-9,12,27-29]. Many studies have shown that to increase the composite repair strength it is necessary to use intermediate agents, most commonly dental adhesive systems [10,16,20-22,30-34]. However, there are no generally accepted rules for their choice.

Despite continued testing of various working procedures and adhesive systems, the composite repairs strength reaches $95 \%$, but occasionally only $36 \%$ of the cohesive strength of the unrepaired composite material $[7,23,27]$. However, these results were often obtained under inconsistent conditions. Most frequently, the composite material was aged before repair for a short period of time up to 14 days
[11,13,15,18-20,24-26,29,35], and only a few studies employed composite materials aged for a longer period ranging from six months to six years, simulating more realistic aging of composite restorations $[7,10,21,36$ 38]. In the oral cavity, the adhesive bond between the existing composite restoration and the repair composite resin is exposed to water, enzymes, bacteria, various chemical substances and mechanical stress, which can initiate its degradation. The chemical substances that might influence the quality of the adhesive bond also include surfactants used as foaming agents in toothpastes. By decreasing the surface tension, the penetration of water into the adhesive joint can be enhanced, accelerating the hydrolysis of the adhesive and reducing the composite repair strength.

The aim of the study was to evaluate the long-term resistance of the adhesive bond between the existing and repair composite materials created with several adhesive systems and different surface treatments subjected to prolonged exposure to water and a surfactant solution. The null hypothesis stated that different surface treatments, adhesive systems and the environment have no impact on the long-term strength of composite repairs.

\section{Materials and Methods}

\section{Specimen preparation}

A micro-hybrid composite material (Filtek Z250, 3M ESPE, Seefeld, Germany) was used in the study. The composite substrates $(n=72)$ were

*Corresponding author: Pavel Bradna, School of Dental Medicine, First Faculty of Medicine of the Charles University and General University Hospital in Prague, Karlovo namesti 32, Prague, 121 11, Czech Republic; Tel: +420 22496 6820, Fax: +420 22496 6840, E-mail: bradna@vus.cz

Received June 18, 2015; Accepted July 07, 2015; Published July 10, 2015

Citation: Comba L, Bradna P, Lenčová E, Dušková J, Děvana Houšová (2015) The Effect of Surface Treatment and Adhesive System on the Durability of Composite Repairs. Dentistry 5: 318. doi:10.4172/2161-1122.1000318

Copyright: $\odot 2015$ Comba L, et al. This is an open-access article distributed under the terms of the Creative Commons Attribution License, which permits unrestricted use, distribution, and reproduction in any medium, provided the original author and source are credited. 
made of shade A4 composite in a Teflon mold $(8 \mathrm{~mm}$ in diameter and 4 $\mathrm{mm}$ in height) using the incremental technique (Figure $1 \mathrm{~A})$. Each $2 \mathrm{~mm}$ increment was light-cured for $20 \mathrm{~s}$ with a halogen curing unit (Elipar TriLight, 3M ESPE, Seefeld, Germany), the light intensity of which, equal to $800 \mathrm{~mW} / \mathrm{cm}^{2}$, was periodically controlled using a calibrated hand-held radiometer EVT 460 (Preciosa, Jablonec nad Nisou, Czech Republic). The last increment was covered with a transparent plastic film and compressed with a glass microscope slide to minimize the thickness of the oxygen-inhibited layer. After curing, the substrates were aged in distilled water at $37^{\circ} \mathrm{C}$ for five months (Figure 1B). Subsequently, the aged specimens were randomly divided into three groups $(n=24)$. Each group was assigned to one of the three following adhesive systems: the three-step etch and rinse adhesive system Optibond FL with $37.5 \%$ phosphoric acid etching gel (Kerr Gel Etchant, Kerr, Orange, USA), the two-step etch and rinse adhesive system Gluma Comfort Bond with $20 \%$ phosphoric acid etching gel (Gluma Etch 20 Gel, Heraeus, Hanau, Germany) and a two-step self-etching adhesive (Clearfil SE Bond, Kuraray, Kurashiki, Japan). The chemical composition and application protocol of all of the materials used in the study are listed in Table 1.

Within each group, the surface of one half of the substrates $(n=12)$ was treated by grinding $(\mathrm{G})$ and the surface of the other half was treated by air abrasion (AA) (Figure 1C). Grinding was performed using P320grit $\mathrm{SiC}$ paper (Buehler Ltd., Lake Bluff, IL, USA) with a median grain size of $46 \mu \mathrm{m}$ mounted in a grinding and polishing machine (Ecomet III, Buehler Ltd., Lake Bluff, IL, USA) under water cooling. This grain size is similar to that of a fine diamond bur ISO 514, which is often used in clinical practice. Air abraded surfaces were prepared with a sandblaster (RONDOflex, KaVo GmbH, Biberach/Riß, Germany) with $50 \mu \mathrm{m} \mathrm{Al}_{2} \mathrm{O}_{3}$ (RONDOflex 2013 Powder, KaVo GmbH, Biberach/Riß, Germany) for $2 \times 30 \mathrm{~s}$, in two perpendicular directions at a working distance of approximately $3 \mathrm{~mm}$, an angle of 90 degrees to the surface and an air pressure of 3.2 Bar. The surfaces were rinsed with water and dried with compressed air. The substrates were inserted into a Teflon mold (8 $\mathrm{mm}$ in diameter and $8 \mathrm{~mm}$ in height), and after the application of the adhesive system and its polymerization according to the manufacturer's recommendations (Table 1), the $4 \mathrm{~mm}$ build-ups were made on the substrates with Filtek Z250, shade B1, using the incremental technique (Figure 1D). Each $2 \mathrm{~mm}$ increment was light-cured for $20 \mathrm{~s}$. A different shade of the composite build-up was chosen to facilitate the detection of the adhesive joint during the specimen trimming. For each adhesive system and preparation method, the composite specimens were further divided into three subgroups $(n=4)$ according to the storage conditions. The composite specimens were then sectioned using a diamond wafer blade $0.3 \mathrm{~mm}$ in thickness at low speed and with water cooling (Isomet low-speed saw, Buehler Ltd., Lake Bluff, IL, USA) perpendicularly to

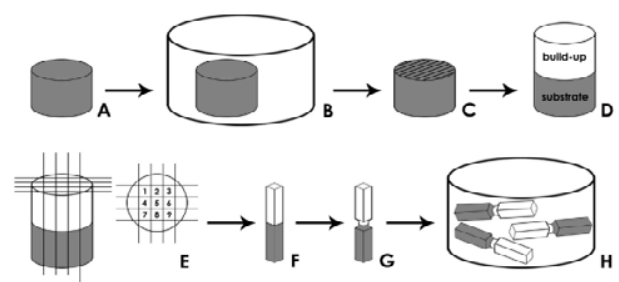

$A=$ composite substrate; $B=$ aging of the composite substrate for five months in distilled water; $\mathrm{C}=$ surface grinding or air abrasion and the application of an adhesive system; $D=$ composite build-up on the aged substrate; $E=$ cutting of the composite specimen; $F=$ composite sticks; $G=$ stick trimming; $H=$ =storing the sticks in different environments.

Figure 1: A schematic diagram of the specimen preparation. the adhesive interface into nine beam-shaped sticks consisting of the aged composite substrate and the composite build-up (Figure 1E-F). The sticks were trimmed at the bonded interface to an hourglass shape with a cross-sectional area of approximately $0.8 \mathrm{~mm}^{2}$ (Figure $1 \mathrm{G}$ ) using a fine diamond bur [39]. The sticks were stored in distilled water for 24 $\mathrm{h}$ or four months, or in a $1.5 \mathrm{wt}$ \% aqueous solution of sodium lauryl sulfate (SLS, Huntsman Surface Sciences Italia SRL, Mantova, Italy) for four months. This SLS concentration was similar to that commonly used in toothpastes. The storage media were kept at $37^{\circ} \mathrm{C}$ and periodically changed at approximately 1 -week intervals (Figure $1 \mathrm{H}$ ). The composite specimens for cohesive strength measurements $(n=4)$ were prepared from the same composite resin as the substrates. Each composite specimen $8 \mathrm{~mm}$ in height was cut into sticks, which were trimmed and stored in distilled water at $37^{\circ} \mathrm{C}$ for $24 \mathrm{~h}$ before testing.

\section{Microtensile bond strength testing}

After the storage period was over, the composite sticks were glued using a flowable composite (Filtek Supreme XT Flow, 3M ESPE, Seefeld, Germany) to the Ciucchi type microtensile testing jig [39], designed to transmit the tensile forces perpendicularly to the bonded interface. The jig was mounted to the universal testing machine (Shimadzu AGS-G, Shimadzu Corp., Japan) and stressed at a crosshead speed of $0.75 \mathrm{~mm} / \mathrm{min}$ until fracture. The fractured area was recorded using a stereomicroscope (Nikon SMZ 2T, Nikon Inc., Japan) equipped with a digital camera (Olympus C-5060) and image analysis software (Quick Photo Industrial, Promicra s.r.o., Czech Republic) to identify the fracture mode and the bonded area. Microtensile bond strength (MPa) was calculated as the force at failure divided by the bonded area.

\section{Fractographic analysis}

The fracture mode was classified as cohesive if fractures propagated within the composite substrate or within the repair composite resin; as adhesive if fractures occurred between substrate and the repair composite materials; or as mixed if both fracture modes were present. The analysis was performed with a stereomicroscope (Nikon SMZ 2T, Nikon Inc., Japan) at a magnification ranging from 20x to 63x. A more detailed analysis of several representative specimens from each group was performed by a scanning electron microscope (SEM, JSM 5500LV, Jeol, Tokyo, Japan) using a secondary electron (SEI) or backscatter electron (BEI) mode, which is more sensitive to the composite microstructure [40].

\section{Characterization of treated surfaces and adhesive layer thickness}

Two composite substrates for each adhesive system were treated with $\mathrm{SiC}$ abrasive paper or air abrasion, then with $37.5 \%$ phosphoric acid gel (Kerr Gel Etchant) for 15 s, and $20 \%$ phosphoric acid gel (Gluma Etch $20 \mathrm{Gel}$ ) for $20 \mathrm{~s}$ or with a self-etching primer (Clearfil SE Bond Primer) for $20 \mathrm{~s}$. The substrates etched with the phosphoric acid were rinsed with water spray, and the substrates treated with the selfetching primer were shortly rinsed with ethanol and then with water.

Four specimens for each adhesive system were cut to produce rectangular sticks. One side of the stick perpendicular to the adhesive interface was polished with P2500-grit SiC paper, then with a $3 \mu \mathrm{m}$ diamond paste on a nylon polishing cloth, and finally with suspension of $1 \mu \mathrm{m} \mathrm{Al} \mathrm{O}_{3}$ on a Texmet polishing cloth (all Buehler Ltd., USA). The polished surface was rinsed several times with distilled water, and cleaned in an ultrasonic bath for $3 \times 3 \mathrm{~min}$ to remove polishing and abrasive particles. The sticks were stored at $37^{\circ} \mathrm{C}$ in distilled water for $24 \mathrm{~h}$. Before all SEM observations, the sticks were dried for one week at 


\begin{tabular}{|c|c|c|c|}
\hline Material & Chemical composition & Application protocol & Batch Number \\
\hline $\begin{array}{l}\text { Filtek Z250 } \\
\text { (3M ESPE, Seefeld, Germany) }\end{array}$ & $\begin{array}{l}\text { Bis-GMA, UDMA, Bis-EMA } \\
\text { Zr/Si filler }\end{array}$ & Light cure (20 s) & $\begin{array}{l}\text { A2: 7YL } \\
\text { A4: } 8 T P\end{array}$ \\
\hline $\begin{array}{l}\text { Optibond FL (OPF) } \\
\text { (Kerr, Orange, USA) }\end{array}$ & $\begin{array}{l}\text { Kerr Gel Etchant: } 37.5 \% \mathrm{H}_{3} \mathrm{PO}_{4} \\
\text { Primer: HEMA, GPDM, PAMM, water, } \\
\text { ethanol, camphorquinone } \\
\text { Adhesive: Bis-GMA, HEMA, GDMA, } \\
\text { camphorquinone, inert mineral fillers }\end{array}$ & $\begin{array}{l}\text { Kerr Gel Etchant: etch (15 s), rinse (15 } \\
\text { s), gently air dry } \\
\text { Primer: apply and rub (15 s), gently air } \\
\text { dry }(5 \mathrm{~s}) \\
\text { Adhesive: apply a thin coat and gently air } \\
\text { dry, light cure }(20 \mathrm{~s})\end{array}$ & $\begin{array}{l}\text { Kerr Gel Etchant:2891204 } \\
\text { Primer: } 2742088 \\
\text { Adhesive: } 2782642\end{array}$ \\
\hline $\begin{array}{l}\text { Gluma Comfort Bond (GLU) } \\
\text { (Heraeus, Hanau, Germany) }\end{array}$ & $\begin{array}{l}\text { Gluma Etch } 20 \text { Gel: } 20 \% \mathrm{H}_{3} \mathrm{PO}_{4} \\
\text { Bond: UDMA, HEMA, 4-META, Poly } \\
\text { (methacrylic-oligo-acrylic acid), ethanol, } \\
\text { water, photoinitiators, stabilizers }\end{array}$ & $\begin{array}{l}\text { Gluma Etch } 20 \text { Gel: etch (20 s), rinse (15 } \\
\text { s), gently air dry (1-2 s) } \\
\text { Bond: apply three coats, wait (15 s), } \\
\text { gently air dry, light cure }(20 \mathrm{~s})\end{array}$ & $\begin{array}{l}\text { Gluma Etch } 20 \text { Gel:285018 } \\
\text { Bond: } 010080\end{array}$ \\
\hline $\begin{array}{l}\text { Clearfil SE Bond (CLF) } \\
\text { (Kuraray, Kurashiki, Japan) }\end{array}$ & $\begin{array}{l}\text { Primer: 10-MDP, HEMA, hydrophilic } \\
\text { dimethacrylate, camphorquinone, N,N- } \\
\text { Diethanol-p-toluidine, water } \\
\text { Bond: } 10-M D P, \text { Bis-GMA, HEMA, } \\
\text { hydrophobic dimethacrylate, } \\
\text { camphorquinone, N,N-diethanol-p- } \\
\text { toluidine }\end{array}$ & $\begin{array}{l}\text { Primer: apply and leave ( } 20 \mathrm{~s}) \text {, gently } \\
\text { air dry } \\
\text { Bond: apply, gently air dry, light cure } \\
(10 \mathrm{~s})\end{array}$ & $\begin{array}{l}\text { Primer: 00852B } \\
\text { Bond: 01250B }\end{array}$ \\
\hline \multicolumn{4}{|c|}{$\begin{array}{l}\text { Abbreviations: Bis-GMA = bisphenol A glycidyl dimethacrylate; UDMA = urethane dimethacrylate; Bis-EMA = bisphenol } \mathrm{A} \text { ethoxy dimethacrylate; HEMA = 2-hydroxyethy } \\
\text { methacrylate; GPDM = glycerolphosphate dimethacrylate; PAMM = phthalic acid monoethyl methacrylate; GDMA= glycerol dimethacrylate; } 4-M E T A=4-\text { methacryloyloxyethy } \\
\text { trimellit anhydride; } M D P=10 \text {-methacryloyloxydecyl dihydrogen phosphate }\end{array}$} \\
\hline
\end{tabular}

Table 1: Chemical composition, application protocol and batch numbers of materials used in the study.

room temperature in air, then for a period of approximately three days at $37^{\circ} \mathrm{C}$ before being sputter-coated with gold (JFC-1200 Fine Coater, Jeol, Tokyo, Japan).

\section{Statistical analysis}

The results of the microtensile bond strength were checked for normality with the Shapiro-Wilk test and then analyzed with a threeway ANOVA (the surface preparation, adhesive system and the storage conditions as variables). Post-hoc multiple comparisons were carried out using Fisher's LSD tests at a significance level of $\alpha=0.05$. In addition, survival analysis using the Weibull two-parameter distribution function was employed. This function is defined by the characteristic strength or scale parameter $\sigma_{o}$ characterizing the bond stress at which $63 \%$ of the specimens fractured and by the shape parameter $\mathrm{m}$, which reflects the variability of bond strength. The higher the $m$ value, the smaller the variability of the results and a higher predictability of the adhesive bond behavior. The Weibull distribution function allows for the calculation of the bond strength $\sigma_{0.05}$, at which the fracture occurred in $5 \%$ of the specimens. Increased values of ${ }_{0.05}$ indicate increasing reliability of the testing system. All of the statistical analyses were performed using STATISTICA 10 (StatSoft Inc., Tulsa, USA). The Weibull distribution parameters were calculated using a maximum likelihood estimation method at a 95\% confidence level. Specimens debonded during sample preparation and handling, due to internal defects, or fractured cohesively were excluded of the statistical calculations [41].

\section{Results}

\section{Microtensile bond strength}

The Shapiro-Wilk test revealed that data were normally distributed, enabling a parametric analysis. The mean bond strengths of the groups treated by air abrasion were higher than those treated by grinding, and exhibited a decrease after four months storage in distilled water and SLS solution (Table 2). Three-way ANOVA revealed that these effects were significant with $(\mathrm{p}<0.00001)$ for surface treatment, $(\mathrm{p}<0.00001)$ for storage conditions and $(\mathrm{p}<0.03)$ for the adhesive system. A statistically significant interaction was found between the surface treatment and storage conditions $(\mathrm{p}<0.009)$. Subsequent post-hoc analysis confirmed significantly higher bond strength in all groups treated by air abrasion rather than by grinding, except for the CLF on air abraded surfaces after
$24 \mathrm{~h}$ (Table 2$)$. Its bond strength was slightly but significantly $(\mathrm{p}<0.004)$ lower than other air abraded groups after $24 \mathrm{~h}$, but comparable ( $\mathrm{p}>0.65)$ with the bond strengths of the groups treated by grinding and stored for $24 \mathrm{~h}$ in water. After four months of storage in water, a statistically significant decrease in the bond strength was found for the GLU $(\mathrm{p}<0.04)$ and CLF $(\mathrm{p}<0.003)$ groups treated by grinding. A decrease in the bond strength after a four-month exposition to SLS solution was significant for OPF $(\mathrm{p}<0.04)$ and GLU $(\mathrm{p}<0.002)$ on ground and GLU ( $p<0.04)$ on air abraded surfaces. Compared with Filtek Z 250's cohesive strength of $45.0 \mathrm{MPa}$, the bond strength of the repairs were significantly lower for all systems, decreasing to 52.2-54.7 or 54.769.3\% after $24 \mathrm{~h}$ up to $23.6-36.9$ or $51.3-62.2 \%$ after 4 months in SLS for the ground and air abraded groups. In the majority of specimens treated by air abrasion, an increased number of mixed and cohesive fractures were observed (Figure 2).

These trends were supported by the bond strength at the $5 \%$ probability of failure $\sigma_{0.05}$ (Table 3 ). With the exception of specimens bonded with GLU to the ground surface and stored for $24 \mathrm{~h}$ in water, the $\sigma_{0.05}$ values were higher for air abraded groups reaching 13.415.5 $\mathrm{MPa}$ and 9.1-9.4 $\mathrm{MPa}$ on ground surface. The $\sigma_{0.05}$ values of the air abraded groups were stable after four months of exposition to water, while groups prepared on ground surfaces decreased in this environment. After exposition to SLS solution, a decrease in the GLU and CLF air abraded groups to 10.4 and $12.0 \mathrm{MPa}$, respectively, was found. In this storage solution, the groups prepared by grinding exhibited even lower values ranging from 5.6-6.7 $\mathrm{MPa}$, which is approximately $22-26 \%$ that of Filtek Z250 $\sigma_{0.05}$ value (Table 3).

\section{Morphology of the prepared surfaces}

Typical unidirectional grooves of different depths and widths caused by the $\mathrm{SiC}$ abrasive particles were observed on the composite surface treated by grinding (Figure 3 ). A detailed analysis at a higher magnification revealed loose filler particles and micro cracks between the grooves, oriented perpendicularly to the direction of grinding. The composite surface treated by air abrasion (Figure 4) seemed at low magnification to be more uniformed than that prepared by grinding. Higher magnification, however, revealed pronounced surface irregularities, such as distinct randomly oriented peaks, pits and fissures. Filler particles debonded from the composite matrix and 


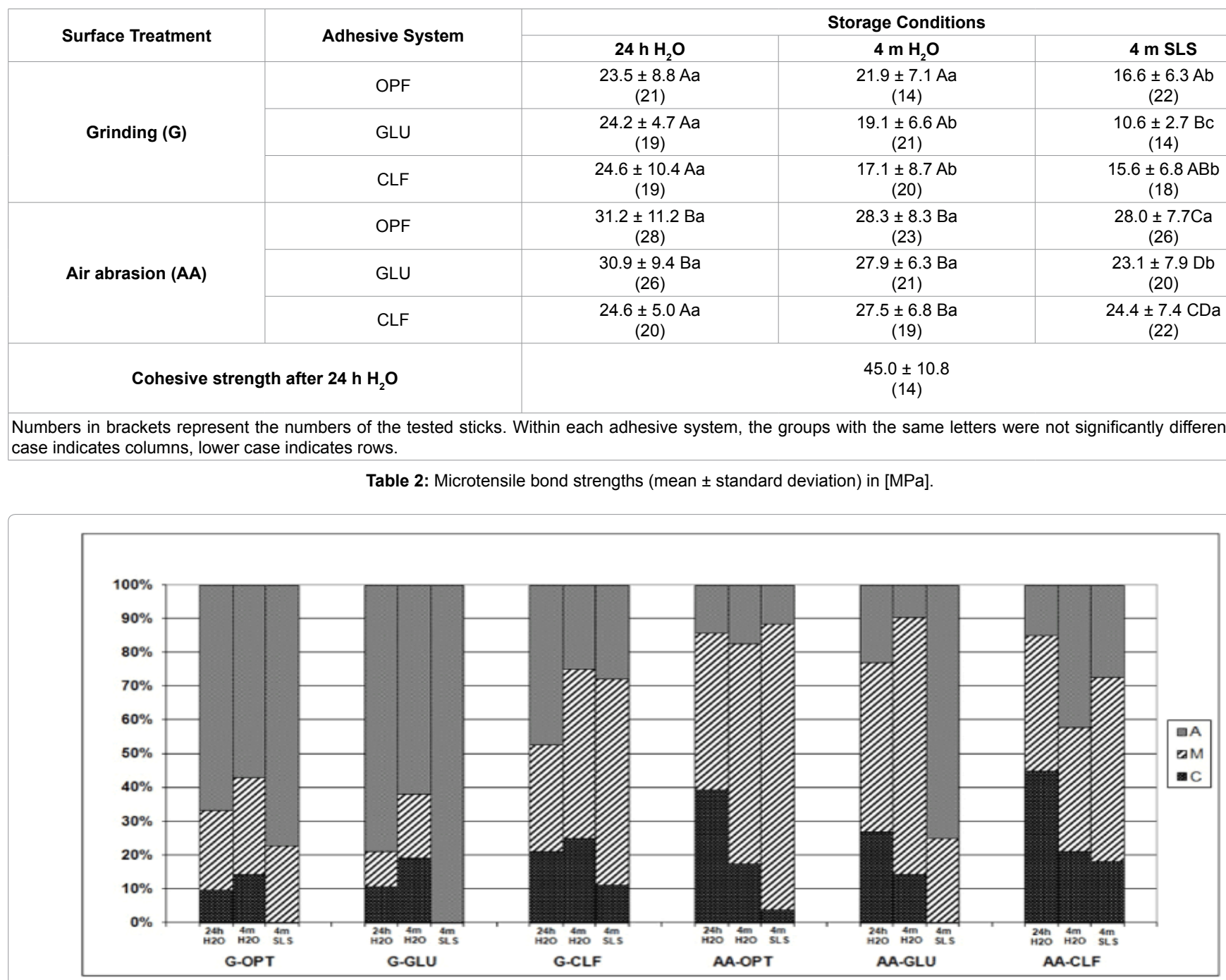

$A=$ adhesive; $M=$ mixed and $C=$ cohesive fractures. Groups treated by grinding $(G)$ or air abrasion (AA).

Figure 2: Distribution of fracture modes in the experimental groups.

\begin{tabular}{|c|c|c|c|c|}
\hline \multirow{2}{*}{$\begin{array}{l}\text { Surface } \\
\text { Treatment }\end{array}$} & \multirow{2}{*}{$\begin{array}{l}\text { Adhesive } \\
\text { System }\end{array}$} & \multicolumn{3}{|c|}{ Storage Conditions } \\
\hline & & $24 \mathrm{~h} \mathrm{H}_{2} \mathrm{O}$ & $4 \mathrm{~m} \mathrm{H}_{2} \mathrm{O}$ & $4 \mathrm{~m} \mathrm{SLS}$ \\
\hline \multirow{3}{*}{ Grinding (G) } & OPF & $\begin{array}{c}(2.8 / 26.3) \\
9.4\end{array}$ & $\begin{array}{c}(3.5 / 24.5) \\
10.4\end{array}$ & $\begin{array}{c}(2.9 / 18.6) \\
6.7\end{array}$ \\
\hline & GLU & $\begin{array}{c}(6.1 / 26.1) \\
16.0\end{array}$ & $\begin{array}{c}(3.2 / 21.4) \\
8.5\end{array}$ & $\begin{array}{c}(4.2 / 11.6) \\
5.7\end{array}$ \\
\hline & CLF & $\begin{array}{c}(2.7 / 27.7) \\
9.1\end{array}$ & $\begin{array}{c}(2.2 / 19.4) \\
5.0\end{array}$ & $\begin{array}{c}(2.6 / 17.6) \\
5.6\end{array}$ \\
\hline \multirow{3}{*}{$\begin{array}{l}\text { Air abrasion } \\
\text { (AA) }\end{array}$} & OPF & $\begin{array}{c}(3.1 / 35.0) \\
13.4\end{array}$ & $\begin{array}{c}(3.7 / 31.3) \\
14.1\end{array}$ & $\begin{array}{c}(4.3 / 30.7) \\
15.5\end{array}$ \\
\hline & GLU & $\begin{array}{c}(3.8 / 34.0) \\
15.5\end{array}$ & $\begin{array}{c}(5.0 / 30.4) \\
16.8\end{array}$ & $\begin{array}{c}(3.3 / 28.8) \\
10.4\end{array}$ \\
\hline & CLF & $\begin{array}{c}(5.2 / 26.6) \\
15.0\end{array}$ & $\begin{array}{c}(4.5 / 30.1) \\
15.6\end{array}$ & $\begin{array}{c}(3.7 / 27.0) \\
12.0\end{array}$ \\
\hline \multicolumn{2}{|c|}{$\begin{array}{l}\text { Cohesive strength after } 24 \\
\qquad \mathrm{~h} \mathrm{H}_{2} \mathrm{O}\end{array}$} & \multicolumn{3}{|c|}{$\begin{array}{c}(4.6 / 49.2) \\
25.9\end{array}$} \\
\hline
\end{tabular}

Table 3: Parameters of Weibull distribution $\left(M / \Sigma_{0}\right)$ and the critical microtensile bond strength $\Sigma_{0.05}[\mathrm{MPa}]$ at a $5 \%$ probability of failure.

sparsely distributed micro cracks could also be identified on the surface. Phosphoric acids and CLF primer treatment removed some loose filler particles from the composite surface.

\section{Adhesive layer thickness}

Figure 5 shows typical images of adhesive layers reaching 20-50 $\mu \mathrm{m}$ for OPT and CLF adhesives, and 5-10 $\mu \mathrm{m}$ for GLU in thickness for both surface treatment methods.

\section{Morphology of fracture surfaces}

Morphology of all adhesively fractured specimens treated by grinding was similar with typical unidirectional grooves caused by the $\mathrm{SiC}$ abrasive particles. On the build-up side of the specimens, filler particles probably loosen from the treated composite could be identified on the top of the grooves (Figure 6).

A different morphology was observed with specimens treated by air abrasion. For GLU, irregular islands of composite separated by cohesively fractured adhesive could be identified (Figure 7). In contrast, more homogenous surfaces for CLF and for OPF covered with its filler particles indicated a fracture line passing cohesively through the adhesive layer (Figure 8). 
Citation: Comba L, Bradna P, Lenčová E, Dušková J, Děvana Houšová (2015) The Effect of Surface Treatment and Adhesive System on the Durability of Composite Repairs. Dentistry 5: 318. doi:10.4172/2161-1122.1000318

\section{Discussion}

While the bond between freshly added increments of composite material is provided by polymerization of free monomers in the oxygeninhibited layer with the monomers of the newly applied material [42], the creation of a bond to aged composite is more complicated. During the aging of composite materials in the oral cavity, the number of double bonds and active radicals that enable chemical bonding between the existing and the repair composite decreases $[43,44]$. In addition, a crosslinked composite polymer matrix strongly limits the penetration of organic solvents, particularly the monomers from adhesive systems, into its structure and thus the formation of an interpenetrating polymer network, contributing to a repaired bond. The bond between the aged and newly applied composite restoration therefore relies on micromechanical retention. When repairing the existing composite restoration, it is first necessary to prepare its surface mechanically to remove the outer layer of the aged composite that is most affected by

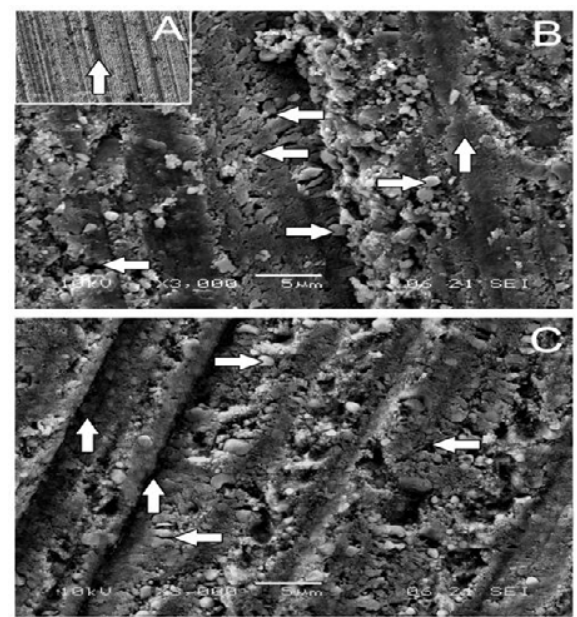

$A=$ magnification $500 \times$; $B=$ magnification $3000 \times$. C = magnification $3000 \times$ after grinding and $\mathrm{H}_{3} \mathrm{PO}_{4}$ treatment. The grooves $(\uparrow)$ caused by the $\mathrm{SiC}$ abrasive particles, debonded filler particles $(\rightarrow)$ and transverse microcracks $(\leftarrow)$ are clearly visible.

Figure 3: SEM image of the composite surface prepared by grinding.

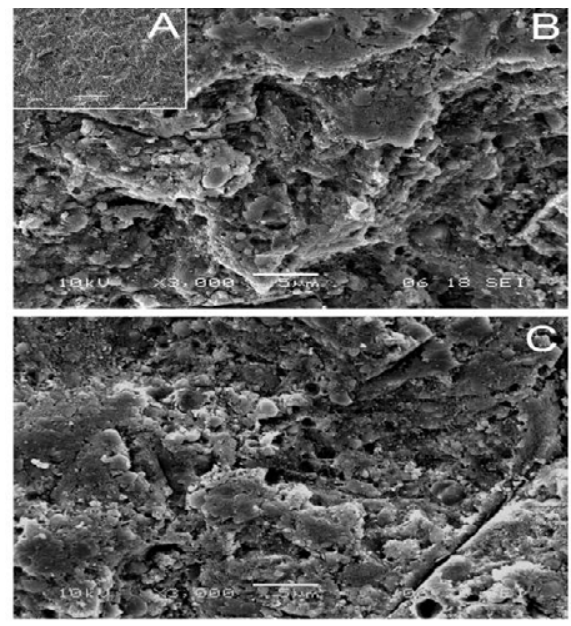

$A=$ magnification $500 x$; $B=$ magnification $3000 x ; C=$ magnification $3000 x$ after air abrasion and $\mathrm{H}_{3} \mathrm{PO}_{4}$ treatment. Pits and fissures created by the impact of alumina particles are visible.

Figure 4: SEM image of the composite surface prepared by air abrasion.
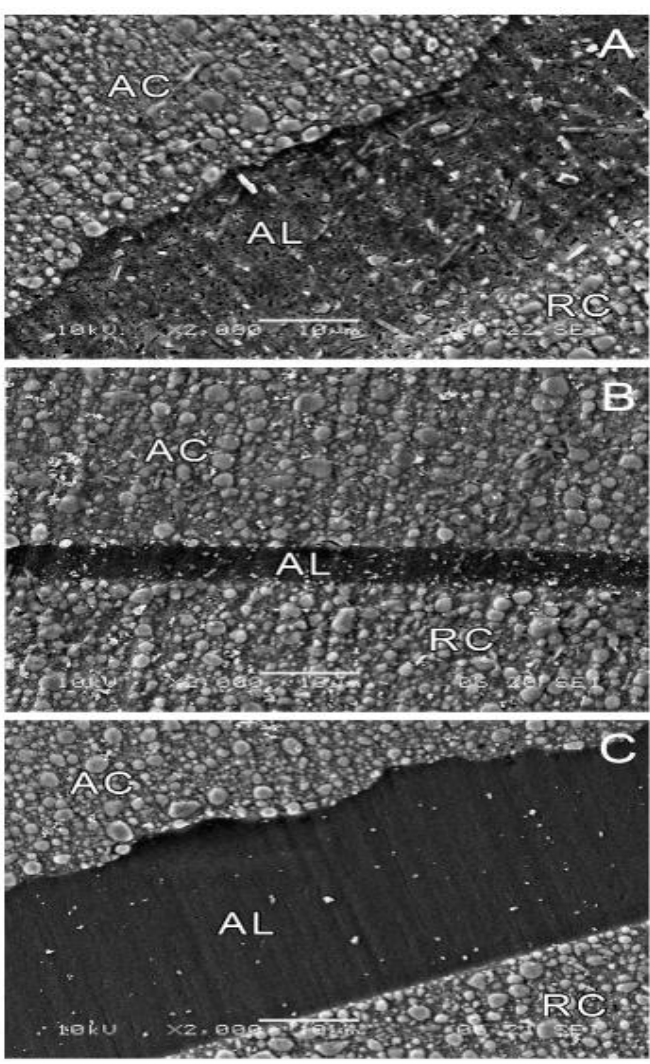

$A=O P F ; B=G L U$ and $C=C L F$. Surface prepared by air abrasion; aged composite $(A C)$, repair composite $(R C)$ and adhesive layer $(A L)$.

Figure 5: Cross-section of the adhesive joints created using OPF, GLU and CLF.
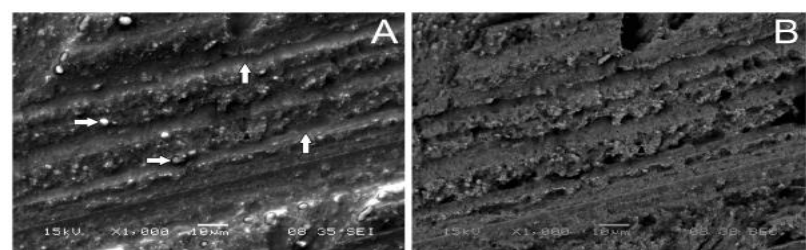

$A=$ surface in SEI mode with typical grooves $(\uparrow)$ and debonded composite filler particles of the grooves $(\rightarrow)$. B=the same area in BEI mode more sensitively reflecting filler particles on the top of the grooves. CLF adhesive, repair composite.

Figure 6: Representative SEM images of adhesively fractured specimens treated by grinding.

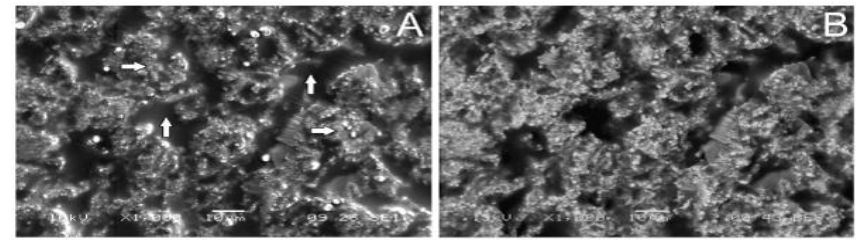

$A=$ surface in SEI mode with pits and fissures filled with adhesive $(\uparrow)$ and islands of the composite material protruding from the adhesive $(\rightarrow)$. B=the same surface in BEI mode.

Figure 7: Representative SEM images of adhesively fractured specimens treated by air abrasion and bonded with GLU 

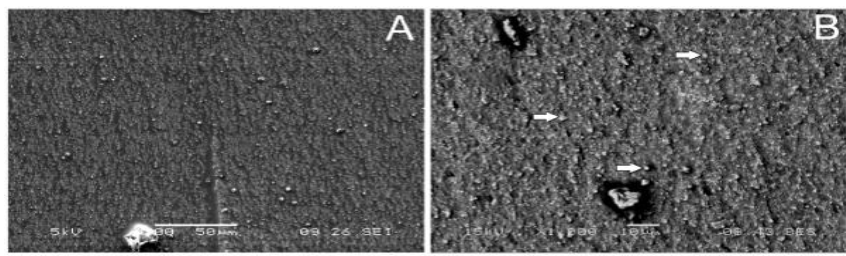

$A=$ bonded with OPF, adhesive filler particles $(\rightarrow)$ indicating cohesive fracture through the adhesive layer. B=bonded with CLF.

Figure 8: Representative SEM images of fractured specimens treated by air abrasion in SEI mode.

saliva or other media, and to create an appropriate surface morphology for micromechanical bonding $[23,45]$. The composite surface is most commonly treated by grinding or air abrasion [7-17,19-22], or by the use of the Co-jet technique [9-11,18,20,46-49] followed by the application of low-viscosity intermediate agents, usually enamel-dentin adhesive systems. In some papers, the silanization of the filler particles on the surface of the repaired composite is used [10,11,15,18,20-22,29,48,49]. Despite a number of studies on this topic, the results evaluating the effect of the surface treatment and adhesive systems in composite repairs remain contradictory. Some authors did not find any differences between the surface treatment procedures $[27,50]$, whereas others did $[10,11,24,25,51]$.

As many of these studies were conducted with composite materials aged for short periods of time, in which the micromechanical and the chemical bond could play a role, in our study, composite materials were aged for five months at $37^{\circ} \mathrm{C}$. We assumed that after this period, stable properties of the aged composite will be achieved, and the bond to such composite would mainly depend on the morphology of its surface. The most important criterion for the selection of an appropriate repair protocol is a long-term durability of the adhesive bond. Thus, the adhesive joints were exposed for four months to water, which is used as a standard degradation environment in the adhesive evaluation. Composite materials and adhesive systems contain hydrophobic monomers that inhibit the penetration of water into their structure decreasing the rate of degradation. Therefore a solution of sodium lauryl sulfate (SLS) at a concentration of $1.5 \%$, which is commonly used in toothpastes, was employed in the study in addition to water. It was expected that a reduction in the surface tension would facilitate the penetration of water into the adhesive joint and accelerate its degradation. An issue regarding composite repairs that still remains unclear is the selection of the adhesive system. Currently, there is a range of adhesive systems for bonding composite materials to enamel and dentin, but none have been developed specifically for composite repairs. For these cases, adhesive systems selected primarily with respect to their adhesion to hard dental tissues were most frequently investigated, which is particularly suitable for repairs involving the interface between the composite material, enamel and dentin [52]. Some studies demonstrated differences in bond strength of composite repairs with the use of different adhesives [12,38,53], while others did not find any difference between them [10,27,32,33,54]. To obtain results with broader applicability, three adhesive systems that differed in application protocols representing the main types of contemporary enamel-dentin adhesives, which were clinically and laboratory proven, were used in our study: the three-step "etch-and-rinse" Optibond FL, consisting of a $37.5 \%$ phosphoric acid gel, hydrophilic primer and hydrophobic bonding agent, applied successively; the two-step "etchand-rinse" Gluma Comfort Bond, which combined primer and bond in one bottle applied in a single step after etching of the surface with a $20 \%$ phosphoric acid gel, and the "self-etch" Clearfil SE Bond, consisting of self-etch primer and bond in separated bottles.

The results of our study (Table 2) showed that in most of the groups the bond strength between the aged and repair composite was significantly higher on the air abraded surface than on the ground surface for all storage conditions. The bond strength on the ground surface showed a greater susceptibility to degradation in water and especially in SLS solution (Table 2) which degradation effect hasn't been investigated so far. An increased risk of failure on ground surface was also indicated by low values of $\sigma_{0.05}$ reaching app. 5-6 MPa which is much lower compared to app. 10-12 MPa for air abraded surface after long-term storage in water or SLS solution (Table 3). The effect of the adhesive system was less pronounced but significant, suggesting higher bond strength and its stability in the environments tested for Optibond FL. Based on these results, the null hypothesis, which stated that there is no effect of surface treatment, environments and the adhesive system, was rejected.

The analysis of the treated surfaces by scanning electron microscopy showed pronounced differences in their morphology. The surface treated by air abrasion was highly irregular, covered with pits and fissures caused by the impact of $\mathrm{Al}_{2} \mathrm{O}_{3}$ particles. Papacchini et al. [25] summarized that this surface with irregularities less than $10 \mu \mathrm{m}$ in size and $5 \mu \mathrm{m}$ in depth [50] enhances the surface area, the surface energy of the composite substrate and increases its wetting properties, improving the bond strength between existing and repair composite materials $[33,55,56]$. On the other hand, unidirectional grooves on the ground surface formed by the $\mathrm{SiC}$ particles and numerous micro cracks perpendicular to their direction and extending into subsurface layers, described first by Söderholm [45], as well as filler particles, partially or completely debonded from the composite matrix were identified on the surface treated by grinding. The formation of these micro cracks may be caused by the limited ability of a strongly crosslinked polymer composite matrix to deform plastically. During grinding, glass composite filler particles transfer the load of abrasive grains to the polymer matrix, and due to its limited plastic deformation, the formation of micro cracks may be induced. The effect of the micro cracks on the bond strength can be contradictory. On the one hand, the surface and subsurface micro cracks increase the contact area between the adhesive system and the surface of the aged composite [45], but they may also act as stress concentrators, initiating fractures of the adhesive joints.

In this study, the bond strength data indicated that air abrasion provides more favourable surface morphology for the micromechanical bond formation. It was also reflected in the fracture modes of the specimens. With groups prepared by grinding, unidirectional grooves on both sides of fractured sticks (Figure 6) suggested that fractures propagated between aged composite surface and the adhesive layer. On the other hand, fractures passing through the adhesive layer of air abraded specimens (Figures 7,8) indicated that the weakest link of the joint is not the aged composite-to-adhesive interface, but the cohesive strength of the adhesive. Due to the relative thinness of the GLU layer (Figure 5), likely caused by a lower concentration of bonding monomers in its composition, typical islands of aged composite protruded from the cohesively fractured adhesive were observed (Figure 7). These results suggested penetration of adhesives into the pits and fissures, and the formation of "tag-like" structures, which contributed to the micromechanical bond more efficiently than the ground grooves. The unidirectional grooves may form path facilitating water penetration into the adhesive joint and its susceptibility to degradation, which 
may be accelerated in the presence of a surfactant. On the other hand, a highly irregular air abraded surface can prolong the path of molecules diffusing through the adhesive joint, and thereby reduce water diffusion and the rate of adhesive joint degradation compared with the ground surface. This may result in a higher durability of repairs on the air abraded surface. It is obvious that this effect will also depend on the bonding efficacy of the adhesive system, and its resistance to water penetration and degradation. Significant effect of the adhesive system observed in this study confirmed this hypothesis. However, the statistical significance $p<0.03$, close to the critical value 0.05 , do not allow for a reliable and unambiguous conclusion on this effect. In addition to high variance of the bond strength measurement, it may arise from the fact that these adhesives rank among laboratory and clinically well-proven systems with high bonding performance.

\section{Conclusion}

It can be concluded that air abrasion may provide increased strength and durability of the composite repairs, especially if combined with well-proven adhesives creating a strong and stable bond to the hard dental tissues.

\section{Acknowledgements}

The authors do not have any financial interest in the companies whose materials are included in this article.

The study was supported by the Ministry of Education, Youth and Sports of Czech Republic, project PRVOUK 28/LF1/6.

\section{References}

1. Brunthaler A, König F, Lucas T, Sperr W, Schedle A (2003) Longevity of direct resin composite restorations in posterior teeth. Clin Oral Investig 7: 63-70.

2. Raj V, Macedo GV, Ritter AV (2007) Longevity of posterior composite restorations. J Esthet Restor Dent 19: 3-5.

3. Gordan VV, Shen C, Riley J 3rd, Mjör IA (2006) Two-year clinical evaluation of repair versus replacement of composite restorations. J Esthet Restor Dent 18: $144-153$

4. Moncada G, Martin J, Fernandez E, Hempel MC, Mjör IA, et al. (2009) Sealing refurbishment and repair of Class I and Class II defective restorations: a three-year clinical trial. J Am Dent Assoc 140: 425-432.

5. Krejci I, Lieber CM, Lutz F (1995) Time required to remove totally bonded tooth-colored posterior restorations and related tooth substance loss. Dent Mater 11: 34-40.

6. Fernandez E, Martin J, Vildosola P, Oliveira Junior OB, Gordan V, et al. (2015) Can repair increase the longevity of composite resins? Results of a 10-year clinical trial. J Dent 43: 279-286.

7. Celik EU, Ergücü Z, Türkün LS, Ercan UK (2011) Tensile bond strength of an aged resin composite repaired with different protocols. J Adhes Dent 13: 359-366.

8. de Melo MA, Moyses MR, dos Santos SG, Alcantara CE, Ribeiro JC (2011) Effects of different surface treatments and accelerated artificial aging on the bond strength of composite resin repairs. Brazilian Oral Research 25: 485-491.

9. Loomans BA, Cardoso MV, Roeters FJ, Opdam NJ, De Munck J, et al. (2011) Is there one optimal repair technique for all composites? Dent Mater 27: 701-709.

10. Rathke A, Tymina Y, Haller B (2009) Effect of different surface treatments on the composite-composite repair bond strength. Clin Oral Investig 13: 317-323.

11. Rodrigues SA, Jr., Ferracane JL, Della Bona A (2009) Influence of surface treatments on the bond strength of repaired resin composite restorative materials. Dent Mater 25: 442-451.

12. Yesilyurt C, Kusgoz A, Bayram M, Ulker M (2009) Initial repair bond strength of a nano-filled hybrid resin: effect of surface treatments and bonding agents. J Esthet Restor Dent 21: 251-260.

13. Valente LL, Silva MF, Fonseca AS, Munchow EA, Isolan CP, et al. (2015) Effect of Diamond Bur Grit Size on Composite Repair. J Adhes Dent.

14. Kimyai S, Oskoee SS, Mohammadi N, Rikhtegaran S, Bahari M, et al. (2015) Effect of different mechanical and chemical surface treatments on the repaired bond strength of an indirect composite resin. Lasers Med Sci 30: 653-659.
15. Kaneko M, Caldas RA, Feitosa VP, Xediek Consani RL, Schneider LF, et al. (2015) Influence of surface treatments to repair recent fillings of silorane-and methacrylate-based composites. J Conserv Dent 18: 242-246.

16. Hemadri M, Saritha G, Rajasekhar V, Pachlag KA, Purushotham R, et al (2015) Shear bond strength of repaired composites using surface treatments and repair materials: an in vitro study. J Int Oral Health 6: 22-25.

17. Duran I, Ural C, Yilmaz B, Tatar N (2015) Effects of Er:YAG laser pretreatment with different energy levels on bond strength of repairing composite materials. Photomed Laser Surg 33: 320-325.

18. Tantbirojn D, Fernando C, Versluis A (2014) Failure Strengths of Composite Additions and Repairs. Oper Dent.

19. Spyrou M, Koliniotou-Koumpia E, Kouros $P$, Koulaouzidou E, Dionysopoulos $P$ (2014) The reparability of contemporary composite resins. Eur J Dent 8: 353-359.

20. Eliasson ST, Tibballs J, Dahl JE (2014) Effect of different surface treatments and adhesives on repair bond strength of resin composites after one and 12 months of storage using an improved microtensile test method. Oper Dent 39: E206-216.

21. Bacchi A, Consani RL, Sinhoreti MA, Feitosa VP, Cavalcante LM, et al (2013) Repair Bond Strength in Aged Methacrylate- and Silorane-based Composites. J Adhes Dent 15: 447-452.

22. Jafarzadeh Kashi TS, Erfan M, Rakhshan V, Aghabaigi N, Tabatabaei FS (2011) An in vitro assessment of the effects of three surface treatments on repair bond strength of aged composites. Oper Dent 36: 608-617.

23. Hannig C, Laubach S, Hahn P, Attin T (2006) Shear bond strength of repaired adhesive filling materials using different repair procedures. $J$ Adhes Dent 8: 35-40.

24. Dall'oca S, Papacchini F, Radovic I, Polimeni A, Ferrari M (2008) Repair potential of a laboratory-processed nano-hybrid resin composite. J Oral Sci 50: 403-412.

25. Papacchini F, Dall'Oca S, Chieffi N, Goracci C, Sadek FT, et al. (2007) Composite-to-composite microtensile bond strength in the repair of a microfilled hybrid resin: effect of surface treatment and oxygen inhibition. $J$ Adhes Dent 9: 25-31.

26. Imbery TA, Gray T, DeLatour F, Boxx C, Best AM, et al. (2014) Evaluation of flexural, diametral tensile, and shear bond strength of composite repairs. Oper Dent 39: E250-260.

27. Cavalcanti AN, De Lima AF, Peris AR, Mitsui FH, Marchi GM (2007) Effect of surface treatments and bonding agents on the bond strength of repaired composites. J Esthet Restor Dent 2: 90-98.

28. Fawzy AS, El-Askary FS, Amer MA (2008) Effect of surface treatments on the tensile bond strength of repaired water-aged anterior restorative microfine hybrid resin composite. J Dent 36: 969-976.

29. Souza EM, Francischone CE, Powers JM, Rached RN, Vieira S (2008) Effect of different surface treatments on the repair bond strength of indirect composites. Am J Dent 21: 93-96.

30. El-Askary FS, Fawzy AS, Abd Elmohsen HM (2009) Tensile bond strength of immediately repaired anterior microfine hybrid restorative composite using nontrimmed hourglass specimens. J Adhes Dent 11: 41-47.

31. Oztas N, Alacam A, Bardakcy Y (2003) The effect of air abrasion with two new bonding agents on composite repair. Oper Dent 28: 149-154.

32. Papacchini F, Radovic I, Magni E, Goracci C, Monticelli F, et al. (2008) Flowable composites as intermediate agents without adhesive application in resin composite repair. Am J Dent 21: 53-58.

33. Shahdad SA, Kennedy JG (1998) Bond strength of repaired anterior composite resins: an in vitro study. J Dent 26: 685-694.

34. Tezvergil A, Lassila LV, Vallittu PK (2003) Composite-composite repair bond strength: effect of different adhesion primers. J Dent 31: 521-525.

35. Ozcan M, Barbosa SH, Melo RM, Galhano GA, Bottino MA (2007) Effect of surface conditioning methods on the microtensile bond strength of resin composite to composite after aging conditions. Dent Mater 23: 1276-1282.

36. Mitsaki-Matsou H, Karanika-Kouma A, Papadoyiannis Y, TheodoridouPahine S (1991) An in vitro study of the tensile strength of composite resins repaired with the same or another composite resin. Quintessence Int 22: 475-481.

37. Papacchini F, Monticelli F, Radovic I, Chieffi N, Goracci C, et al. (2007) The 
Citation: Comba L, Bradna P, Lenčová E, Dušková J, Děvana Houšová (2015) The Effect of Surface Treatment and Adhesive System on the Durability of Composite Repairs. Dentistry 5: 318. doi:10.4172/2161-1122.1000318

application of hydrogen peroxide in composite repair. J Biomed Mater Res B Appl Biomater 82: 298-304.

38. Teixeira EC, Bayne SC, Thompson JY, Ritter AV, Swift EJ (2005) Shear bond strength of self-etching bonding systems in combination with various composites used for repairing aged composites. J Adhes Dent 7: 159-164.

39. Pashley DH, Carvalho RM, Sano H, Nakajima M, Yoshiyama M, et al. (1999) The microtensile bond test: a review. J Adhes Dent 1: 299-309.

40. Scougall-Vilchis RJ, Hotta Y, Hotta M, Idono T, Yamamoto K (2009) Examination of composite resins with electron microscopy, microhardness tester and energy dispersive X-ray microanalyzer. Dent Mater J 28: 102-112.

41. Scherrer SS, Cesar PF, Swain MV (2010) Direct comparison of the bond strength results of the different test methods: a critical literature review. Dent Mater 26: 78-93.

42. Li J (1997) Effects of surface properties on bond strength between layers of newly cured dental composites. J Oral Rehabil 24: 358-360.

43. Dall'Oca S, Papacchini F, Goracci C, Cury AH, Suh BI, et al. (2007) Effect of oxygen inhibition on composite repair strength over time. Journal of Biomedical Materials Research 81: 493-498.

44. Tezvergil A, Lassila LV, Yli-Urpo A, Vallittu PK (2004) Repair bond strength of restorative resin composite applied to fiber-reinforced composite substrate. Acta Odontol Scand 62: 51-60.

45. Soderholm KJ, Roberts MJ (1991) Variables influencing the repair strength of dental composites. Scand J Dent Res 99: 173-180.

46. Ozcan M, Cura C, Brendeke J (2010) Effect of aging conditions on the repair bond strength of a microhybrid and a nanohybrid resin composite. J Adhes Dent 12: 451-459.
47. Ozcan M, Pekkan G (2013) Effect of Different Adhesion Strategies on Bond Strength of Resin Composite to Composite-dentin Complex. Oper Dent 38: 63-72.

48. Perriard J, Lorente MC, Scherrer S, Belser UC, Wiskott HW (2009) The effect of water storage, elapsed time and contaminants on the bond strength and interfacial polymerization of a nanohybrid composite. J Adhes Dent 11: 469-478.

49. Rinastiti M, Ozcan M, Siswomihardjo W, Busscher HJ (2009) Immediate repair bond strengths of microhybrid, nanohybrid and nanofilled composites after different surface treatments. J Dent 38: 29-38.

50. Bonstein T, Garlapo D, Donarummo J Jr, Bush PJ (2005) Evaluation of varied repair protocols applied to aged composite resin. J Adhes Dent 7 : 41-49.

51. Pontes AP, Oshima HM, Pacheco JF, Martins JL, Shinkai RS (2005) Shea bond strength of direct composite repairs in indirect composite systems. Gen Dent 53: 343-347.

52. Hannig C, Hahn P, Thiele PP, Attin T (2003) Influence of different repair procedures on bond strength of adhesive filling materials to etched enamel in vitro. Oper Dent 28: 800-807.

53. Lucena-Martin C, Gonzalez-Lopez S, Navajas-Rodriguez de Mondelo JM (2001) The effect of various surface treatments and bonding agents on the repaired strength of heat-treated composites. J Prosthet Dent 86: 481-488.

54. Costa TR, Ferreira SQ, Klein-Junior CA, Loguercio AD, Reis A (2010) Durability of surface treatments and intermediate agents used for repair of a polished composite. Oper Dent 35: 231-237.

55. Bouschlicher MR, Cobb DS, Vargas MA (1999) Effect of two abrasive systems on resin bonding to laboratory-processed indirect resin composite restorations. J Esthet Dent 11: 185-196.

56. Goldstein, White SN (1995) Intraoral esthetic repair of dental restorations. Esthet Dent 7: 219-227. 